\title{
WEB Device Shape Changes in Elastase-Induced Aneurysms in Rabbits
}

\author{
(D) Y. Ding, (DD. Dai, (D) A. Rouchaud, (D). Janot, (D). Asnafi, (DD.F. Kallmes, and (D) Kadirvel
}

\begin{abstract}
BACKGROUND AND PURPOSE: While WEB devices have been shown to be safe and effective for aneurysm treatment, WEB-shape modification compression has been associated with incomplete aneurysm occlusion. We explored the relationship between occlusion rates and WEB-shape modification in different WEB device types in an experimental aneurysm model.
\end{abstract}

MATERIALS AND METHODS: Elastase-induced aneurysms were created in rabbits and treated with dual-layer $(n=12)$, single-layer $(n=12)$, or single-layer sphere $(n=12)$ WEB devices. Aneurysms were followed up either at 3 or 12 months. Angiographic occlusion was graded using the WEB Occlusion Scale: grade I, complete; grade II, complete but recess filling; grade III, residual neck; or grade IV, residual aneurysm. WEB-shape modification and histologic features were also analyzed.

RESULTS: Grade I or II occlusion was seen in 16 (44\%) aneurysms, and grade I, II, or III ("adequate") occlusion was observed in 22 (61.1\%) aneurysms at follow-up. WEB-shape modification was observed in 22 (61.1\%) aneurysms. WEB-shape modification was higher in single-layer (9/12) and dual-layer (10/12) devices compared with single-layer sphere devices (3/12). Aneurysms with WEB-shape modification had a higher level of thrombus organization in the dome compared with those without WEB-shape modification (68\% [15/22] versus 50\% [7/14]). WEB-shape modification was not correlated with angiographic or histologic outcomes but was significantly correlated with levels of fibrosis and smooth muscle cells in the aneurysm.

CONCLUSIONS: WEB-shape modification is not associated with incomplete aneurysm occlusion of WEB devices in the rabbit model but may be related to connective tissue formation and the healing response to WEB device implantation.

ABBREVIATIONS: FD = flow diverter; SMA = smooth muscle actin; WSM = WEB-shape modification; DL = dual-layer; SL = single-layer; SLS = single-layer sphere

D uring the past 2 decades, the treatment of intracranial aneurysms has rapidly evolved from the single option of open skull surgical clipping to the increasingly common use of minimally invasive endovascular techniques. While endovascular coiling has been shown to offer significant advantages over an open surgical approach, it is still associated with significant limitations. These include treatment-associated morbidity of at least $5 \%-7 \%$,

Received March 27, 2018; accepted after revision September 5, 2020. From the Department of Radiology (Y.D., D.D., S.A., D.F.K., R.K.), Mayo Clinic, Rochester, Minnesota; Department of Interventional Neuroradiology (A.R.), University Hospital, Limoges, France; Neuroradiology Department (K.J.), University Hospital of Tours, Tours, France; and Department of Radiology (S.A.), Emory University, Atlanta, Georgia.

This study was supported, in part, by National Institutes of Health grant No. NS076491 (R. Kadirvel).

Please address correspondence to Ramanathan Kadirvel, PhD, Department of Radiology, Mayo Clinic, 200 First ST SW, Rochester, MN 55905; e-mail: kadir@mayo.edu

-- Indicates open access to non-subscribers at www.ajnr.org http://dx.doi.org/10.3174/ajnr.A6899 a high aneurysm recurrence rate (as high as $20 \%-30 \%$ in some series), and low aneurysm occlusion rates. ${ }^{1}$

Flow diverters (FDs) are innovative and promising devices used to treat complex and/or wide-neck aneurysms. ${ }^{2,3}$ They divert blood away from aneurysms, and their use has expanded since inception. ${ }^{4,5}$ Use of endoluminal FDs, however, necessitates the use of antiplatelet therapy, which can be problematic for ruptured aneurysms. Unfortunately, the use of FDs does not eliminate the possibility of delayed aneurysm rupture, a thromboembolic event, and parent artery stenosis. ${ }^{6}$

The Woven EndoBridge (WEB) device (MicroVention) is a completely intrasaccular FD device, which was designed to treat challenging, wide-neck bifurcation aneurysms that are difficult to embolize safely and effectively with other existing treatment approaches. ${ }^{7,8}$ From the original dual-layer (DL) to current single-layer (SL) design, WEB devices have shown a good safety profile and a high rate of adequate occlusion both in experimental and clinical studies. ${ }^{9-16}$ In the meantime, WEB-shape modification (WSM) has been reported in the literature and could 
potentially be associated with the approximately $15 \%$ rate of incomplete/inadequate aneurysm occlusion observed in the published WEB Intrasaccular Therapy (WEB-IT) trial. ${ }^{17}$ However, this phenomenon has not been well-understood until now because other researchers have reported that this shape change did not impact the anatomic outcome after WEB deployment. ${ }^{18}$ In this study, we compared the occlusion rates of DL, SL, and single-layer sphere (SLS) WEBs in rabbit elastase (Worthington Biochemical)-induced aneurysm models and evaluated the relationship between WSM using histologic results and angiographic occlusion rates.

\section{MATERIALS AND METHODS Aneurysm Creation}

Elastase-induced aneurysms were created in $36 \mathrm{New}$ Zealand white rabbits. Animal procedures were approved by the Institutional Animal Care and Use Committee at Mayo Clinic. Aneurysm-creation procedures were performed using an elastase-induction model as previously described. ${ }^{19}$ Endovascular treatment of each aneurysm was undertaken at least 3 weeks after aneurysm creation. ${ }^{20}$

\section{Devices}

WEB devices are classified according to shape and the number of mesh layers each one contains. DL devices consist of 2 layers of braided, nitinol wire mesh. SL and SLS devices consist of a single layer of braided, nitinol/platinum wire mesh; however, SLS implants have a more rounded 3D shape than the "barrel-like" SL and DL devices. The specific qualities of the WEB devices have been previously described. ${ }^{21,22}$

\section{Device Deployment}

The WEB device deployment procedure has been reported previously. ${ }^{7,8}$ The right femoral artery was briefly exposed. A 5F sheath (Envoy; Cordis) was inserted, $500 \mathrm{U}$ of heparin was injected, and a $5 \mathrm{~F}$ catheter was then advanced into the brachiocephalic trunk from the aortic arch. DSA was performed through the guide catheter. A 0.027-inch ID (interior diameter) microcatheter (VIA-27; Sequent Medical) was advanced into the aneurysm lumen over a microguidewire (Transend-14; Stryker). Appropriately sized devices were placed in the aneurysm cavity for each device $(n=12$ [DL], $n=12$ [SL], $n=12$ [SLS]). DSA was performed immediately following device placement. No animals received antiplatelet therapy during the course of the study.

\section{Follow-Up and Euthanasia}

Angiographic evaluation was completed immediately after device implantation and again at follow-up. The cohort was divided into 2 subgroups preselected for euthanasia at 3 months $(n=6[\mathrm{DL}], n=6$ [SL], $n=6$ [SLS]) and 12 months $(n=6$ [DL], $n=6$ [SL], $n=6$ [SLS]), respectively, by intravenous injection with a lethal dose of pentobarbital through the ear vein. Following euthanasia, aneurysm tissue was harvested and placed in a $10 \%$ formalin solution.

\section{Aneurysm Grading and WSM Assessment}

The degree of angiographic aneurysm occlusion at follow-up was graded as follows: grade I, complete; grade II, complete but with recess filling; grade III, residual neck; or grade IV, residual aneurysm. ${ }^{23,24}$ Two reviewers independently evaluated the angiographic occlusion, and disagreements were resolved by a third reviewer. Angiographic occlusion outcome was dichotomized into either complete occlusion (grade I or II) or incomplete occlusion (grade III or IV). Grades I, II, and III were considered adequate. The distance between proximal and distal device markers was measured on unsubtracted angiographic images. WSM was defined as a change in distance $(\leq-10 \%$ to $\geq 10 \%)$ between markers at follow-up compared with immediate postdevice deployment.

\section{Histopathologic Processing and Analysis}

A histopathologist who was blinded to the angiographic results did the processing and analysis for healing evaluation. Aneurysm samples were processed at $1000-\mu \mathrm{m}$ intervals in a coronal orientation, permitting long-axis sectioning of the aneurysm neck, with use of an IsoMet Low Speed Saw (Buehler). After the device segments were removed under a dissecting microscope, the samples were then re-embedded in paraffin, sectioned at $4 \mu \mathrm{m}$, and stained with hematoxylin-eosin.

Histologic healing of aneurysms was assessed using an ordinal scale. ${ }^{25}$ The extent of blood clot organization within the aneurysm and the neointimal coverage of the aneurysm neck were evaluated. Tissue compaction, seen as a concave surface of clot tissue toward the aneurysm dome, was also analyzed. The degree of inflammation within each aneurysm was scored as 0 (no inflammatory cell infiltration); 1 (minimal or mild: scant, scattered inflammatory cell infiltration); 2 (moderate: patchy-butlocalized or limited inflammatory cell infiltration); or 3 (marked: attenuated, diffuse inflammatory cell infiltration).

Masson trichrome staining was performed to evaluate collagen deposition within the aneurysm; collagen deposition within the aneurysm dome was segmented and quantified using the previously described method. ${ }^{26}$ The fibrosis ratio (total area of fibrosis within the aneurysmal cavity divided by the total area of the aneurysmal cavity) was calculated for each aneurysm.

Immunohistochemical staining of smooth muscle cells in tissue sections was performed with smooth muscle actin (SMA). ${ }^{27}$ The SMA-positive area was segmented and quantified with the same method used for collagen deposition as described above.

\section{Statistical Analysis}

Continuous variables were described as mean [SD] and compared using a Student $t$ test. Categoric variables were presented as number (percentage) and compared using the Fisher exact test. The correlation between WSM and aneurysm occlusion was assessed by the Spearman rank correlation. The correlation between WSM and aneurysm geometries, histologic healing, fibrosis, and smooth muscle actin levels was evaluated by simple linear regression. A $P$ value $<.05$ was considered statistically significant.

\section{RESULTS}

\section{Angiographic Findings}

All aneurysms were implanted with appropriately sized devices. No morbidity or mortality was observed throughout the study.

In the group of rabbits selected for euthanasia at 3 months $(n=18)$, grade I or II occlusion was achieved in $9(50 \%)$ 
aneurysms at follow-up. Within this group, 6 rabbits were treated with the DL device: 1 (16.7\%) showed grade I occlusion, 3 (50.0\%) showed grade II occlusion, 1 (16.7\%) showed grade III occlusion, and 1 (16.7\%) showed grade IV occlusion. For the 6 rabbits treated with the SL device, 1 (16.7\%) showed grade I occlusion, 2 (33.3\%) showed grade III occlusion, and $3(50.0 \%)$ showed grade IV occlusion. In the final subgroup $(n=6)$ treated with the SLS device, 3 (50.0\%) rabbits showed grade I occlusion,

Table 1: Aneurysm occlusion grading summary

\begin{tabular}{lcccc}
\hline \multicolumn{1}{c}{ Group $^{\text {a }}$} & $\begin{array}{c}\text { DL, No. } \\
(\%)\end{array}$ & $\begin{array}{c}\text { SL, No. } \\
(\%)\end{array}$ & $\begin{array}{c}\text { SLS, No. } \\
(\%)\end{array}$ & $\begin{array}{c}\text { Total, No. } \\
(\%)\end{array}$ \\
\hline 3-Month group & & & & \\
Grade I & $1(16.7)$ & $1(16.7)$ & $3(50.0)$ & $5(27.8)$ \\
Grade II & $3(50.0)$ & $0(0)$ & $1(16.7)$ & $4(22.2)$ \\
Grade III & $1(16.7)$ & $2(33.3)$ & $0(0)$ & $3(16.7)$ \\
Grade IV & $1(16.7)$ & $3(50.0)$ & $2(33.3)$ & $6(33.3)$ \\
Total & 6 & 6 & 6 & 18 \\
12-Month group & & & & \\
Grade I & $3(50.0)$ & $1(16.7)$ & $1(16.7)$ & $5(27.8)$ \\
Grade II & $1(16.7)$ & $0(0)$ & $1(16.7)$ & $2(11.1)$ \\
Grade III & $0(0)$ & $2(33.3)$ & $1(16.7)$ & $3(16.7)$ \\
Grade IV & $2(33.3)$ & $3(50.0)$ & $3(50.0)$ & $8(44.4)$ \\
Total & 6 & 6 & 6 & 18 \\
\hline
\end{tabular}

${ }^{a}$ Grade I represents complete occlusion; grade II, complete occlusion with recess filling; grade III, residual neck; grade IV, residual aneurysm.

\section{Device shape change}

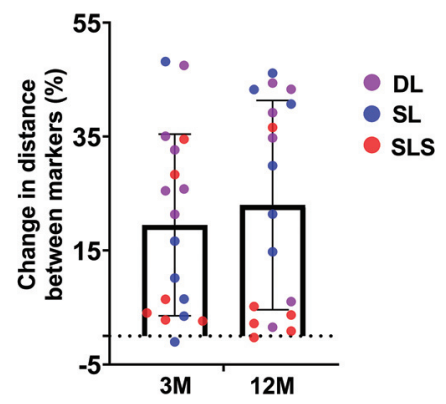

FIG 1. Range of WEB device shape change by time and device configuration. The change in distance between the distal and proximal markers of the device at follow-up compared with that immediately posttreatment. Positive values denote device shortening; negative values represent device elongation. Device elongation is seen in only 2 cases, both of which have device elongation of $<2 \%$. $3 \mathrm{M}$ indicates 3 months; $12 \mathrm{M}, 12$ months.
1 (16.7\%) showed grade II occlusion, and 2 (33.3\%) showed grade IV occlusion.

In the 12-month group at follow-up $(n=18), 7$ (38.9\%) aneurysms had grade I or 2 occlusion. Of the 6 rabbits treated with the DL device, 3 (50.0\%) showed grade I occlusion, 1 (16.7\%) showed grade II occlusion, and 2 (33.3\%) showed grade IV occlusion. For the 6 rabbits treated with the SL device, 1 (16.7\%) showed grade I occlusion, 2 (33.3\%) showed grade III occlusion, and 3 (50.0\%) showed grade IV occlusion. For the rabbits treated with the SLS device, 1 (16.7\%) showed grade I occlusion, 1 (16.7\%) showed grade II occlusion, 1 (16.7\%) showed grade III occlusion, and the remaining 3 (50.0\%) showed grade IV occlusion (Table 1).

In a pooled angiographic analysis, $16(44 \%)$ aneurysms (9 at 3 months and 7 at 12 months) demonstrated complete occlusion and $22(61.1 \%)$ aneurysms (12 at 3 months, and 10 at 12 months) showed adequate occlusion. No significance was found in complete or adequate occlusion rates between the 3-and 12-month groups $(P=.74)$. DL $(75 \%, 9 / 12)$ devices demonstrated a higher percentage of adequate aneurysm occlusion compared with SLS $(58.3 \%, 7 / 12 ; P=.68)$ and SL $(50 \%, 6 / 12 ; P=.04)$ devices.

\section{WEB-Shape Modification}

WSM was observed in 22 (61\%) aneurysms (Fig 1), of which half (5 with complete occlusion, 6 with incomplete occlusion) were in the 3-month group and the remaining half (4 with complete occlusion, 7 with incomplete occlusion) were in the 12-month group (Table 2). WSM was not statistically associated with aneurysm neck width or height (Fig 2). There were no significant differences in occlusion grades in aneurysms with or without WSM (9 with complete occlusion, 13 with incomplete occlusion versus 7 with complete occlusion and 7 with incomplete occlusion; $P=.73$ ) (Fig 1). Furthermore, no correlation was found between the percentage of WSM and the occlusion grade. Most interesting, SLS had significantly less WSM $(25 \%, 3 / 12)$ compared with the DL $(83 \%, 10 / 12$; $P=.012)$ and SL $(75 \%, 9 / 12 ; P=.039)$ devices.

\section{Histologic Findings}

The mean histologic healing score was not significantly different between the 3- and 12-month groups (5.6 [SD , 2.6] versus 4.2 [SD, $2.5]$; $P=.11$ ), but it was significantly higher in aneurysms with complete occlusion compared with those with incomplete occlusion (6.39 [SD, 2.07] versus 2.80 [SD, 1.75]). Histologic evaluation of aneurysm sacs showed a combination of loose connective tissue and thrombus (unorganized, organized, and poorly organized).

Table 2: WSM and aneurysm occlusion by device type

\begin{tabular}{|c|c|c|c|c|c|c|c|c|}
\hline \multirow[b]{2}{*}{$\begin{array}{c}\text { Follow-Up, } \\
\text { Occlusion } \\
\text { Group }^{a}\end{array}$} & \multicolumn{2}{|c|}{$\mathrm{DL}(n=12)$} & \multicolumn{2}{|c|}{$\mathrm{SL}(n=12)$} & \multicolumn{2}{|c|}{ SLS $(n=12)$} & \multicolumn{2}{|c|}{ Total $(n=36)$} \\
\hline & $\begin{array}{c}\text { With WSM, } \\
\text { No. (\%) }\end{array}$ & $\begin{array}{l}\text { Without } \\
\text { WSM, No. } \\
(\%)\end{array}$ & $\begin{array}{c}\text { With } \\
\text { WSM, No. } \\
(\%)\end{array}$ & $\begin{array}{l}\text { Without } \\
\text { WSM, No. } \\
(\%)\end{array}$ & $\begin{array}{c}\text { With } \\
\text { WSM, No. } \\
(\%)\end{array}$ & $\begin{array}{l}\text { Without } \\
\text { WSM, No. } \\
(\%)\end{array}$ & $\begin{array}{c}\text { With } \\
\text { WSM, No. } \\
(\%)\end{array}$ & $\begin{array}{l}\text { Without } \\
\text { WSM, No. } \\
(\%)\end{array}$ \\
\hline \multicolumn{9}{|l|}{3 Months } \\
\hline Grade I or II & $4(33.3)$ & 0 & 0 & $1(8.3)$ & $1(8.3)$ & $3(25.0)$ & 5 (13.9) & 4 (11.1) \\
\hline Grade III or IV & $2(16.7)$ & 0 & $3(25.0)$ & $2(16.7)$ & $1(8.3)$ & $1(8.3)$ & $6(16.7)$ & $3(8.3)$ \\
\hline \multicolumn{9}{|l|}{12 Months } \\
\hline Grade I or II & $3(25.0)$ & $1(8.3)$ & $1(8.3)$ & 0 & 0 & $2(16.7)$ & 4 (11.1) & $3(8.3)$ \\
\hline Grade III or IV & $1(8.3)^{\prime}$ & $1(8.3)$ & $5(41.7)$ & 0 & $1(8.3)$ & $3(25.0)$ & $7(19.4)$ & 4 (11.1) \\
\hline Total & $10(83.3)$ & $2(16.7)$ & $9(75.0)$ & $3(25.0)$ & $3(25.0)$ & $9(33.3)$ & $22(61.1)$ & $14(38.9)$ \\
\hline
\end{tabular}

${ }^{a}$ Grade I represents complete occlusion; grade II, complete occlusion with recess filling; grade III, residual neck; grade IV, residual aneurysm. 

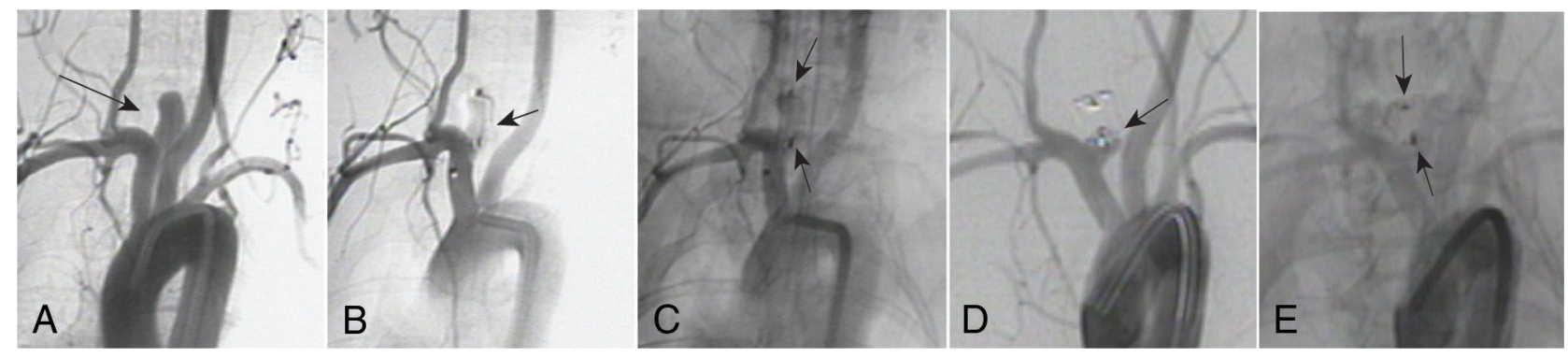

FIG 2. WEB shape changes at 3 months following device implantation. A, Anteroposterior DSA image before device implantation shows an aneurysm cavity (arrow). B, The DSA image immediately after SL device deployment shows complete aneurysm occlusion (arrow). C, Unsubtracted image of $B$ shows proximal and distal markers (arrows) of the WEB device. D, DSA image at 3-month follow-up shows a residual neck (arrow). E, Unsubtracted image of $D$ shows device compression. Note that the distance between the proximal and distal markers (arrows) is reduced compared with that in C, indicating a change in shape.

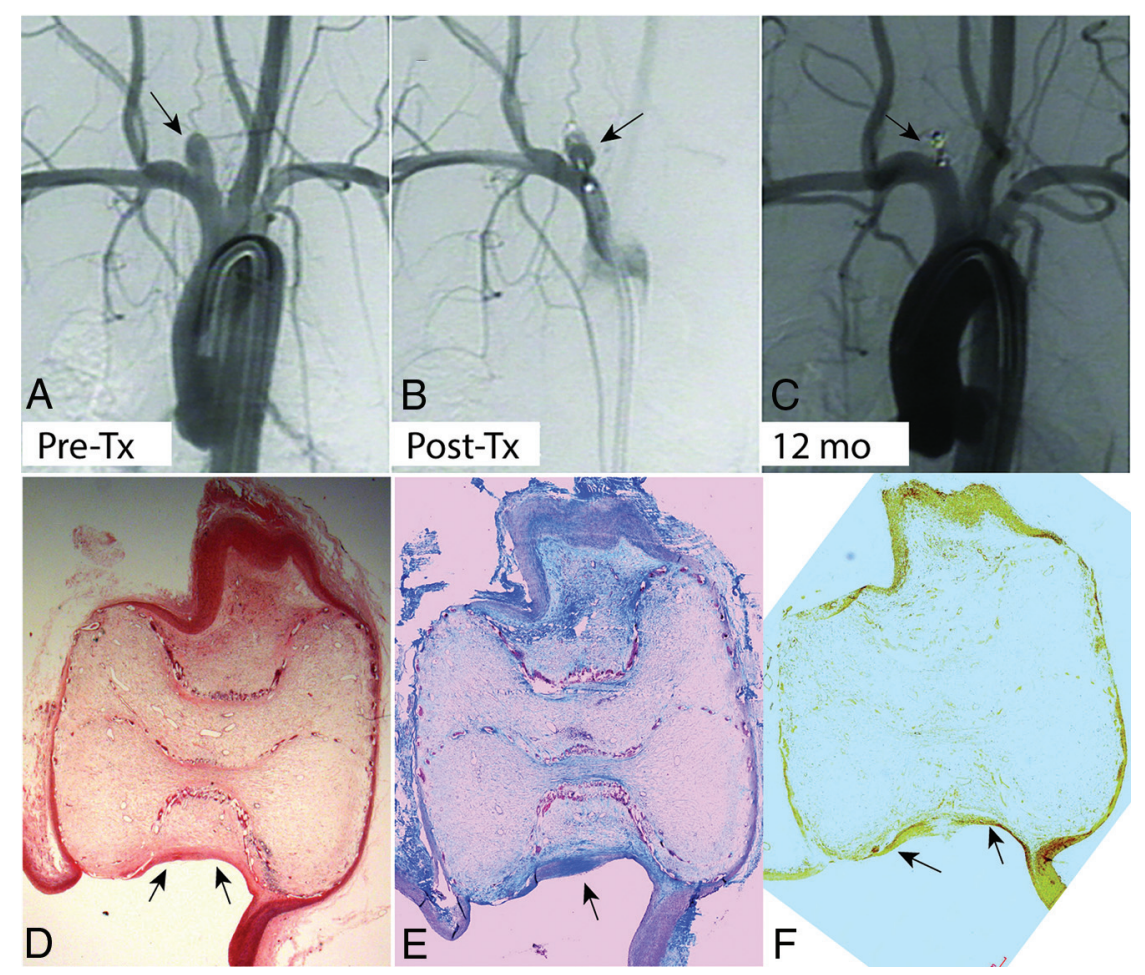

FIG 3. A, Anteroposterior DSA before aneurysm treatment (arrow). B, A DSA image immediately after DL device deployment shows residual aneurysm (arrow). C, A DSA image at 12 months shows complete occlusion (arrow) with substantial shortening of the device. $D$, Photomicrograph of a section (hematoxylin-eosin, original magnification $\times 12.5$ ) demonstrates an aneurysm sac filled with loose connective tissue, except for a small neck remnant. A neointimal layer completely traverses the neck interface near the proximal device markers (arrows). E, Photomicrograph of a section shows moderate collagen deposition throughout the aneurysm cavity (Masson trichrome stain, original magnification $\times 2.3$ ). Relatively high collagen content was noted near the proximal marker (arrow). F, Photomicrograph of a section shows the presence of smooth muscles throughout the aneurysm dome, as well as in the neointimal lining bridging the neck (arrows) (SMA immunostain, original magnification $\times 2.0)$. Tx indicates treatment.

Aneurysms that demonstrated complete occlusion had more organized thrombus $(76 \%, 16 / 21)$, while aneurysms that exhibited incomplete occlusion had unorganized thrombus $(60 \%, 9 / 15)$ in the aneurysm dome. Most aneurysms showed open areas with no tissue filling and a neck remnant with a concave surface toward the dome (75\% [12/16] in the complete occlusion group versus $90 \%$
[18/20] in the incomplete occlusion group). Inflammation within the aneurysm lumen was absent or mild.

Aneurysms with the WSM showed a high level of organized thrombus compared with those without WSM (68\% [15/22] versus 50\% [7/14], $P=.09$ ) (Fig 3). The mean histologic healing score, inflammation score, fibrosis percentage, and SMA percentage was 5.0 [SD, 2.3], 1.5 [SD, 0.6], 15.9 [SD, 14.8], and 12.6 [SD, 9.6], respectively, in aneurysms with WSM, and 4.7 [SD, 3.2], 1.2 [SD, 0.8], 9.6 [SD, 8.0], and 9.5 [SD, 8.2], respectively, in aneurysms without WSM. There were no statistically significant differences in histologic healing, inflammation, fibrosis, and SMA between aneurysms with and without WSM. However, the percentage of WSM was moderately correlated with both fibrosis $(r=0.37$, $P=.02)$ and SMA levels $(r=0.36$, $P=.032$ ) (Fig 4). WSM was not significantly correlated with either total histologic healing or inflammation.

\section{DISCUSSION}

Our study, which aimed to delineate the underlying mechanisms of WSM in WEB devices, demonstrates that WSM does not correlate with angiographic aneurysm occlusion or total histologic healing outcomes in the rabbit aneurysm model. However, WSM is positively associated with collagen and SMA levels, supporting the hypothesis that WSM is likely more related to aneurysm healing than external (eg, hemodynamic) compression alone.

The underlying mechanisms of WSM or compression could be multifaceted (eg, device size and construction, exact anatomic 
Fibrosis

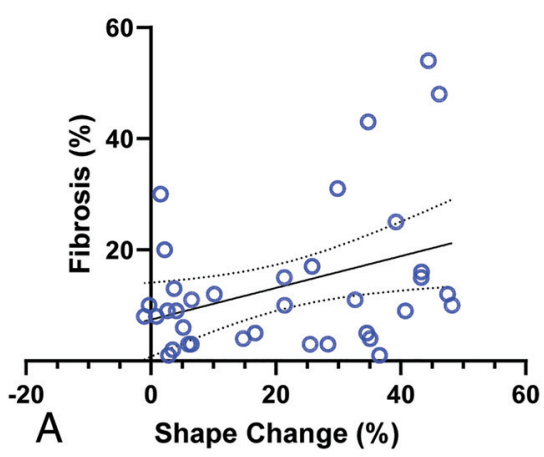

SMA

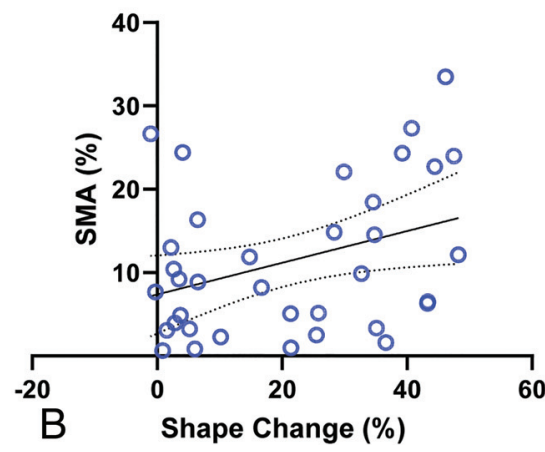

FIG 4. Correlation of the degree of device shape change with histologic features. Linear regression shows a significant positive correlation between the percentage of device length change and fibrosis $(A)$ and SMA (B). Straight lines indicate regression; bowed lines indicate $95 \% \mathrm{Cl}$.

A high stringent limit may provide different results. Third, we did not evaluate numerous other factors, including mechanical and hemodynamic factors, which could influence the device shape changes.

\section{CONCLUSIONS}

WSM is not associated with incomplete aneurysm occlusion in the rabbit model but may be related to connective tissue formation and collagen deposition after WEB implantation.

Disclosures: Yonghong Ding-RELATED: Grant: National Institutes of Health NS071766, NS097038.* David F. Kallmes_RELATED: Grant: ev3/ Covidien*; Consulting Fee or Honorarium: ev3/ configuration of aneurysm geometry and surrounding vessels, parent artery, aneurysm neck). Computational fluid dynamics simulations have shown that WEB device compression was positively correlated with computational fluid dynamics-derived inflow into the aneurysm. ${ }^{28}$ In endoluminal FDs, pore density has been positively associated with aneurysm occlusion. Pore density at the proximal WEB device marker is relatively high compared with that in endoluminal devices, ${ }^{29,30}$ and it is highly unlikely that device compression would lead to reduced pore density at the neck. Rouchaud et $\mathrm{al}^{31}$ demonstrated, in coiled aneurysms, that a higher level of collagen in the aneurysm dome could trigger coil retraction from the neck orifice into the aneurysm cavity, resulting in aneurysm recurrence. Our findings suggest that WEB devices could behave like coils in the vascular microenvironment and result in device compression, and the contractile properties of connective tissue components in WEB-implanted aneurysms could lead to WSM. Proper endothelial cell growth across the pores of FDs in the aneurysm neck is also considered critical for aneurysm occlusion, in addition to the change in blood hemodynamics, for the mechanistic action of FDs. Endoluminal FDs placed in the healthy parent artery act as scaffolds for endothelial cell migration and neointima formation. In contrast, intrasaccular FDs are implanted in the aneurysm cavity, which represent a nonfunctional endothelium and a smooth-muscle layer and could explain the lack of neointimal coverage at the neck.

The observed WSM rate of $62 \%$ in the rabbit model is similar to that reported in clinical studies for the WEB device. ${ }^{32-36}$ Although DL WEB devices had higher adequate occlusion rates compared with SL devices in this study, the DL devices also demonstrated higher WSM. Given the small sample sizes and the difference of a single result providing statistical significance, taken together, these results suggest that WSM is not well-correlated with either device type.

Our study has several limitations. First, the variation in the angiographic working projection angle resulted in inaccurate measurements of the distance between device markers. Second, we arbitrarily defined $10 \%$ of the device as a threshold for WSM. Institutes of Health, Surmodics, Benvenue Medi-cal, and MicroVention.* *Money paid to the institution.

\section{REFERENCES}

1. De Leacy RA, Fargen KM, Mascitelli JR, et al. Wide-neck bifurcation aneurysms of the middle cerebral artery and basilar apex treated by endovascular techniques: a multicentre, core lab adjudicated study evaluating safety and durability of occlusion (BRANCH). J Neurointerv Surg 2019;11:31-36 CrossRef Medline

2. Duman E, Coven I, Yildirim E, et al. Endovascular treatment of wide necked ruptured saccular aneurysms with flow-diverter stent. Turk Neurosurg 2017;27:362-67 CrossRef Medline

3. Simgen A, Junk D, Reith W. Flow diverter: a new therapy option for intracranial aneurysms. Radiologe 2012;52:1118-24 CrossRef Medline

4. Pumar JM, Mosqueira A, Cuellar H, et al. Expanding the use of flow diverters beyond their initial indication: treatment of small unruptured aneurysms. J Neurointerv Surg 2018;10:245-48 CrossRef Medline

5. Kallmes DF, Ding YH, Dai D, et al. A new endoluminal, flow-disrupting device for treatment of saccular aneurysms. Stroke 2007;38:234652 CrossRef Medline

6. Lubicz B, Collignon L, Raphaeli G, et al. Flow-diverter stent for the endovascular treatment of intracranial aneurysms: a prospective study in 29 patients with 34 aneurysms. Stroke 2010;41:2247-53 CrossRef Medline

7. Ding YH, Lewis DA, Kadirvel R, et al. The Woven EndoBridge: a new aneurysm occlusion device. AJNR Am J Neuroradiol 2011;32:607-11 CrossRef Medline

8. Ding YH, Dai D, Schroeder D, et al. Experimental testing of the dual-layer Woven EndoBridge device using an elastase-induced aneurysm model in rabbits. Interv Neuroradiol 2016;22:299-303 CrossRef Medline

9. Papagiannaki C, Spelle L, Januel AC, et al. WEB intrasaccular flow disruptor-prospective, multicenter experience in 83 patients with 85 aneurysms. AJNR Am J Neuroradiol 2014;35:2106-11 CrossRef Medline

10. Pierot L, Gubucz I, Buhk JH, et al. Safety and efficacy of aneurysm treatment with the WEB: results of the WEBCAST 2 study. AJNR Am J Neuroradiol 2017;38:1151-55 CrossRef Medline

11. Pierot L, Klisch J, Liebig T, et al. WEB-DL endovascular treatment of wide-neck bifurcation aneurysms: long-term results in a European series. AJNR Am J Neuroradiol 2015;36:2314-19 CrossRef Medline

12. Pierot L, Arthur A, Spelle L, et al. Current evaluation of the safety and efficacy of aneurysm treatment with the WEB device. AJNR Am J Neuroradiol 2016;37:586-87 CrossRef Medline

13. Lescher S, Du Mesnil de Rochemont R, Berkefeld J. Woven EndoBridge (WEB) device for endovascular treatment of complex
Covidien.* UNRELATED: Sequent Medical, Codman Neurovascular, National 
unruptured aneurysms: a single center experience. Neuroradiology 2016;58:383-90 CrossRef Medline

14. van Rooij WJ, Peluso JP, Bechan RS, et al. WEB treatment of ruptured intracranial aneurysms. AJNR Am J Neuroradiol 2016;37:1679-83 CrossRef Medline

15. Sivan-Hoffmann R, Gory B, Riva R, et al. One-year angiographic follow-up after WEB-SL endovascular treatment of wide-neck bifurcation intracranial aneurysms. AJNR Am J Neuroradiol 2015; 36:2320-24 CrossRef Medline

16. Gherasim DN, Gory B, Sivan-Hoffmann R, et al. Endovascular treatment of wide-neck anterior communicating artery aneurysms using WEB-DL and WEB-SL: short-term results in a multicenter study. AJNR Am J Neuroradiol 2015;36:1150-54 CrossRef Medline

17. Cognard C, Januel AC. Remnants and recurrences after the use of the WEB intrasaccular device in large-neck bifurcation aneurysms. Neurosurgery 2015;76:522-30 CrossRef Medline

18. Herbreteau D, Bibi R, Narata AP, et al. Are anatomic results influenced by WEB shape modification? Analysis in a prospective, single-center series of 39 patients with aneurysms treated with the WEB. AJNR Am J Neuroradiol 2016;37:2280-86 CrossRef Medline

19. Altes TA, Cloft HJ, Short JG, et al. 1999 ARRS Executive Council Award: creation of saccular aneurysms in the rabbit-a model suitable for testing endovascular devices. American Roentgen Ray Society. AJR Am J Roentgenol 2000;174:349-54 CrossRef Medline

20. Fujiwara NH, Cloft HJ, Marx WF, et al. Serial angiography in an elastase-induced aneurysm model in rabbits: evidence for progressive aneurysm enlargement after creation. AJNR Am J Neuroradiol 2001;22:698-703 Medline

21. Caroff J, Mihalea C, Klisch J, et al. Single-layer WEBs: intrasaccular flow disrupters for aneurysm treatment-feasibility results from a European study. AJNR Am J Neuroradiol 2015;36:1942-46 CrossRef Medline

22. Pierot L, Moret J, Turjman F, et al. WEB treatment of intracranial aneurysms: feasibility, complications, and 1-month safety results with the WEB DL and WEB SL/SLS in the French Observatory. AJNR Am J Neuroradiol 2015;36:922-27 CrossRef Medline

23. Fiorella D, Arthur A, Byrne J, et al. Interobserver variability in the assessment of aneurysm occlusion with the WEB aneurysm embolization system. J Neurointerv Surg 2015;7:591-95 CrossRef Medline

24. Rouchaud A, Brinjikji W, Ding YH, et al. Evaluation of the angiographic grading scale in aneurysms treated with the WEB device in 80 rabbits: correlation with histologic evaluation. AJNR Am J Neuroradiol 2016;37:324-29 CrossRef Medline
25. Dai D, Ding Y-H, Lewis DA, et al. A proposed ordinal scale for grading histology in elastase-induced, saccular aneurysms. AJNR Am J Neuroradiol 2006;27:132-38 Medline

26. Fitzgerald $S$, Wang $S$, Dai D, et al. Orbit image analysis machine learning software can be used for the histological quantification of acute ischemic stroke blood clots. PLos One 2019;14:e0225841 CrossRef Medline

27. Dai D, Ding YH, Danielson MA, et al. Histopathologic and immunohistochemical comparison of human, rabbit, and swine aneurysms embolized with platinum coils. AJNR Am J Neuroradiol 2005;26:2560-68 Medline

28. Caroff J, Mihalea C, Da Ros V, et al. A computational fluid dynamics (CFD) study of WEB-treated aneurysms: can CFD predict WEB “compression" during follow-up? J Neuroradiol 2017;44:262-68 CrossRef Medline

29. Klisch J, Sychra V, Strasilla C, et al. The Woven EndoBridge cerebral aneurysm embolization device (WEB II): initial clinical experience. Neuroradiology 2011;53:599-607 CrossRef Medline

30. Maragkos GA, Dmytriw AA, Salem MM, et al. Overview of different flow diverters and flow dynamics. Neurosurgery 2020;86:52134 CrossRef Medline

31. Rouchaud A, Brinjikji W, Dai D, et al. Autologous adipose-derived mesenchymal stem cells improve healing of coiled experimental saccular aneurysms: an angiographic and histopathological study. J Neurointerv Surg 2018;10:60-65 CrossRef Medline

32. Pierot L, Moret J, Turjman F, et al. WEB treatment of intracranial aneurysms: clinical and anatomic results in the French Observatory. AJNR Am J Neuroradiol 2016;37:655-59 CrossRef Medline

33. Armoiry X, Turjman F, Hartmann DJ, et al. Endovascular treatment of intracranial aneurysms with the WEB device: a systematic review of clinical outcomes. AJNR Am J Neuroradiol 2016;37:868-72 CrossRef Medline

34. Behme D, Berlis A, Weber W. Woven EndoBridge Intrasaccular flow disrupter for the treatment of ruptured and unruptured wide-neck cerebral aneurysms: report of 55 cases. AJNR Am J Neuroradiol 2015;36:1501-06 CrossRef Medline

35. Arthur AS, Molyneux A, Coon AL, et al. WEB-IT Study investigators. The safety and effectiveness of the Woven EndoBridge (WEB) system for the treatment of wide-necked bifurcation aneurysms: final 12-month results of the pivotal WEB Intrasaccular Therapy (WEBIT) Study. J Neurointerv Surg 2019;11:924-30 CrossRef Medline

36. Pierot L, Moret J, Barreau X, et al. Safety and efficacy of aneurysm treatment with WEB in the cumulative population of three prospective, multicenter series. J Neuronterv Surg 2018;10:553-62 CrossRef Medline 